\title{
Effect of Apigenin on Leishmania amazonensis Is Associated with Reactive Oxygen Species Production Followed by Mitochondrial Dysfunction
}

\author{
Fernanda Fonseca-Silva, ${ }^{\dagger}$ Marilene M. Canto-Cavalheiro, ${ }^{\dagger}$ Rubem F. S. Menna-Barreto, ${ }^{\ddagger}$
} and Elmo E. Almeida-Amaral ${ }^{*} \dagger$

${ }^{\dagger}$ Laboratório de Bioquímica de Tripanosomatídeos and ${ }^{\ddagger}$ Laboratório de Biologia Celular, Instituto Oswaldo Cruz, Fundação Oswaldo Cruz, Av. Brasil 4365, Manguinhos, Rio de Janeiro, Brazil

ABSTRACT: Leishmaniasis is an important neglected disease caused by protozoa of the genus Leishmania that affects more than 12 million people worldwide. Leishmaniasis treatment requires the administration of toxic and poorly tolerated drugs, and parasite resistance greatly reduces the efficacy of conventional medications. Apigenin (1), a naturally occurring plant flavone, has a wide range of reported biological effects. In this study, antileishmanial activity of $\mathbf{1}$ in vitro was investigated, and its mechanism of action against Leishmania amazonensis promastigotes was described. Treatment with 1 for $24 \mathrm{~h}$ resulted in concentration-dependent inhibition of cellular proliferation $\left(\mathrm{IC}_{50}=23.7 \mu \mathrm{M}\right.$ ) and increased reactive oxygen species (ROS) generation. Glutathione and $N$-acetyl-L-cysteine protected L. amazonensis from the effects of 1 and reduced ROS levels after the treatment. By contrast, oxidized glutathione did not reduce the levels of ROS caused by $\mathbf{1}$ by not preventing the proliferation inhibition. Apigenin $\mathbf{1}$ also induced an extensive swelling in parasite mitochondria, leading to an alteration of the mitochondrial membrane potential, rupture of the trans-Golgi network, and cytoplasmic vacuolization. These results demonstrate the leishmanicidal effect of $\mathbf{1}$ and suggest the involvement of ROS leading to mitochondrial collapse as part of the mechanism of action.

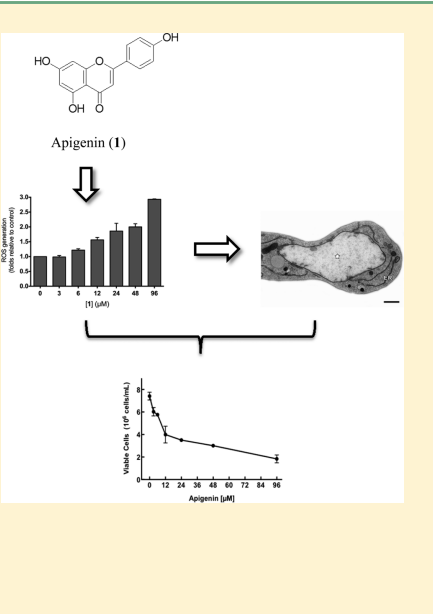

$\mathrm{L}$ eishmaniasis is an important neglected disease caused by protozoa of the genus Leishmania that affects more than 12 million people worldwide; 350 million people are considered at risk of contracting leishmaniasis, and some 2 million new cases occur yearly. ${ }^{1,2}$ The severity of disease caused by various Leishmania species varies widely, ranging from cutaneous and/or mucosal to visceral infection. Leishmaniasis treatment requires the administration of toxic and poorly tolerated drugs, such as pentavalent antimonials, the first-line compounds used to treat leishmaniasis, pentamidine, amphotericin B, and miltefosine. However, the parasite resistance greatly reduces the efficacy of conventional medications. 3,4

Natural sources such as plants are a major resource for the discovery of new lead molecules for neglected diseases. ${ }^{5}$ Isolated compounds, including some flavonoids, have been reported to present significant antiprotozoal activities. ${ }^{6-12}$ Apigenin (1), a naturally occurring plant flavone that is abundantly distributed in common fruits and vegetables and is recognized as a bioactive flavonoid, has a wide range of reported biological effects, including antioxidant, antihypertensive, anti-inflammatory, antimicrobial, and antiprotozoal activities. ${ }^{13,14}$<smiles>O=c1cc(-c2ccc(O)cc2)oc2cc(O)cc(O)c12</smiles>

In this study, antileishmanial activity of $\mathbf{1}$ in vitro and its mechanism of action against Leishmania amazonensis promastigotes are described. Compound $\mathbf{1}$ inhibited promastigote proliferation in a concentration-dependent manner. This leishmanicidal activity was reactive oxygen species (ROS)-dependent and promoted mitochondrial dysfunction, culminating in parasite death.

\section{RESULTS AND DISCUSSION}

Antiparasitic activity of $\mathbf{1}$ against $L$. donovani, Trypanosoma brucei rhodesiense, T. cruzi, Encephalitozoon intestinalis, and Cryptosporidium parvum has been described. ${ }^{15,16}$ To determine the effect of $\mathbf{1}$ on the proliferation of $L$. amazonensis, promastigotes were incubated with different concentrations of $1(3-96 \mu \mathrm{M})$ for $24 \mathrm{~h}$. Concentration-dependent inhibition of cellular proliferation was observed $(p<0.001)$, with an $\mathrm{IC}_{50}$ of $23.7 \mu \mathrm{M}$ (Figure 1A). Compound $1(96 \mu \mathrm{M})$ inhibited $75 \%$ of the proliferation of L. amazonensis after $24 \mathrm{~h}$.

To confirm the inhibition of the cellular proliferation of L. amazonensis by $\mathbf{1}$, the stable intracytoplasmic dye CFSE (5,6carboxyfluorescein succinimidyl ester) was used to evaluate cellular proliferation by measuring the relative fluorescence intensity by flow cytometry. ${ }^{17,18}$ The CFSE stain forms stable conjugates with aliphatic amines in the cytoplasm. ${ }^{19} \mathrm{~A}$ remarkable decrease in the CFSE fluorescence of untreated promastigotes was observed after $24 \mathrm{~h}$ (Figure 1B), indicating

Received: January 21, 2015

Published: March 13, 2015 
A

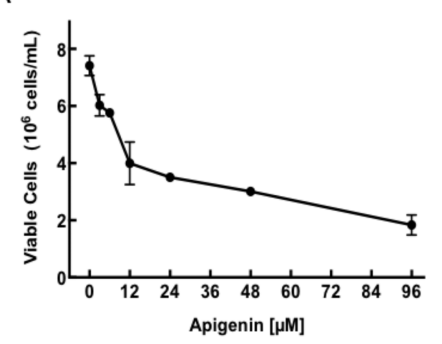

B
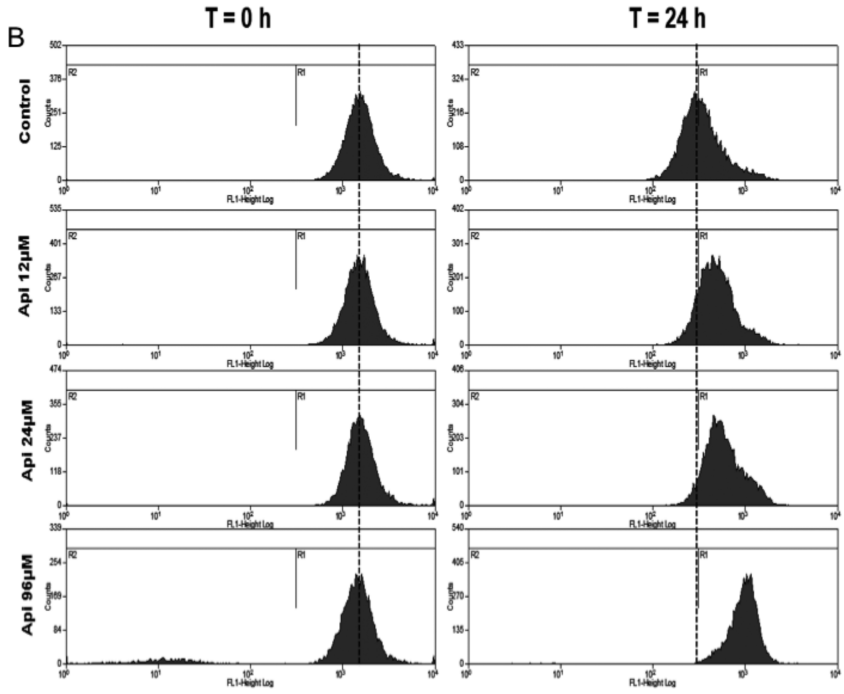

Figure 1. Effect of apigenin (1) on the cellular proliferation of $L$. amazonensis. Promastigotes were cultivated in Schneider's Drosophila medium at $26^{\circ} \mathrm{C}$ for $24 \mathrm{~h}$ in the absence or presence of $1(3-96 \mu \mathrm{M})$. Cellular proliferation was determined by direct counting of the number of parasites using a Neubauer chamber (A) or using the stable intracytoplasmic dye CFSE (B). In the control (absence of 1), the same volume of dimethylsulfoxide (solvent of $\mathbf{1}$ ) was added to the growth medium. The values are presented as the mean \pm standard error of three different experiments. The histograms are representative of three independent experiments.

cell division. This decrease in CFSE fluorescence was inhibited in a concentration-dependent manner by $\mathbf{1}(12,24$, and $96 \mu \mathrm{M})$, clearly indicating inhibition of cell division. These results demonstrate the antileishmanial activity of $\mathbf{1}$ against promastigote forms. Similar effects have been observed for others flavonoids, such as quercetin and (-)-epigallocatechin 3-O-gallate, which inhibit the cellular proliferation of L. amazonensis in a concentration-dependent manner., ${ }^{9,10}$ However, compound $\mathbf{1}$ was more potent than quercetin (-)-epigallocatechin 3-O-gallate, which demonstrated an $\mathrm{IC}_{50}$ of $31.4 \mu \mathrm{M}$ at $48 \mathrm{~h}$ and an $\mathrm{IC}_{50}$ of $63 \mu \mathrm{M}$ at $120 \mathrm{~h}$.

Although flavonoids are known to exhibit antioxidant properties, some studies have demonstrated pro-oxidant activities in vitro. ${ }^{10-12,20}$ Treatment with 1 for $24 \mathrm{~h}$ increased ROS generation in $L$. amazonensis in a concentration-dependent manner $(p<0.01)$ (Figure 2). ROS levels in L. amazonensis treated with $1(96 \mu \mathrm{M})$ were 2.9-fold higher than those of the control. ROS production in a concentration-dependent manner has also been reported for the exposure of L. amazonensis and $L$. braziliensis promastigotes to quercetin ${ }^{10}$ and $(-)$-epigallocatechin 3-O-gallate, ${ }^{12}$ respectively. This ROS production induced a severe reduction in the number of parasites. ROS levels were 4.4-fold higher with $96 \mu \mathrm{M}$ quercetin at $48 \mathrm{~h}$ and 2.9-fold higher with $500 \mu \mathrm{M}(-)$-epigallocatechin 3-O-gallate at $72 \mathrm{~h}$.

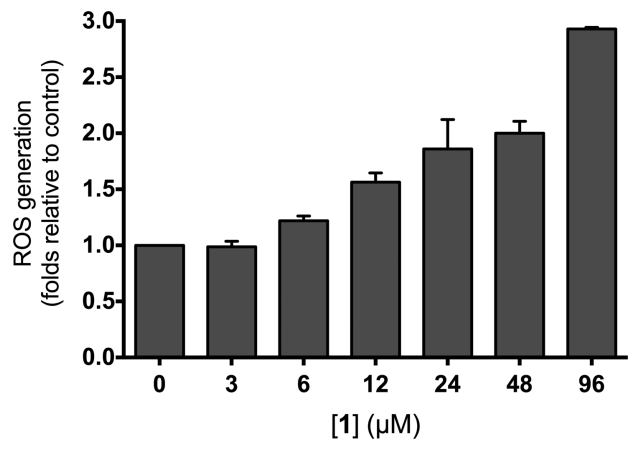

Figure 2. ROS production in L. amazonensis treated with $\mathbf{1}$. Promastigotes cultivated in Schneider's Drosophila medium at $26{ }^{\circ} \mathrm{C}$ for $24 \mathrm{~h}$ in the absence or presence of 1 (3-96 $\mu \mathrm{M})$. ROS was measured using the fluorescent dye $\mathrm{H}_{2} \mathrm{DCFDA}$ as described in the Experimental Section. The data are expressed as the fold increase in ROS production relative to the control. The values presented are the mean \pm standard error of three different experiments.

In L. amazonensis, reduced glutathione $(\mathrm{GSH})$ is a component of trypanothione, a major antioxidant of this parasite, $^{21}$ and intracellular GSH levels can be increased by treatment with the antioxidant $\mathrm{N}$-acetyl-L-cysteine (NAC). ${ }^{22}$ To confirm that the inhibitory effects of $\mathbf{1}$ are mediated by ROS production, L. amazonensis promastigotes were preincubated with GSH or NAC $(300 \mu \mathrm{M})$. GSH and NAC protected $L$. amazonensis from the effects of $\mathbf{1}$ (Figure $3 \mathrm{~A}$ ) and reduced ROS levels in cells treated with $\mathbf{1}$ (Figure $3 \mathrm{~B}$ ). By contrast, oxidized glutathione (GSSG) did not reduce ROS levels and did not protect against the proliferation inhibition caused by $\mathbf{1}$, suggesting ROS production as a possible mechanism for the induction of $L$. amazonensis promastigote death. This mechanism is the basis of various antiprotozoal medications used to combat parasites in infected cells. ${ }^{23}$

Damage to the mitochondrial membrane potential $\left(\Delta \Psi_{\mathrm{m}}\right)$ can be induced by the direct addition of ROS in vitro or the induction of ROS production by chemical agents. ${ }^{24,25}$ Transmission electron microscopy images of untreated promastigotes (panels A and B) and promastigotes treated with 1 for $24 \mathrm{~h}$ (12 $\mu \mathrm{M}$, panels $\mathrm{C}$ and D; $24 \mu \mathrm{M}$, panels $\mathrm{E}$ and $\mathrm{G}$; and $96 \mu \mathrm{M}$, panel $\mathrm{H}$ ) are shown in Figure 4. The treatment induced extensive swelling of the parasite mitochondria (Figure 4C-G; white stars), and the inner mitochondrial membrane was severely damaged, with a washed-out matrix appearance and decreased matrix electron density (Figure 4C-G). Concentric membrane structures were also observed inside the organelle (Figure 4C,E,F; black arrow). Treatment with $12 \mu \mathrm{M}$ 1 (Figure 4D) also led to the appearance of endoplasmic reticulum (ER) profiles surrounding the cellular structures and cytosolic vacuolization (V). The highest concentration employed $(96 \mu \mathrm{M})$ strongly affected the mitochondrial ultrastructure (white star), resulting in a washed-out appearance of this organelle matrix and loss of cristae (Figure $4 \mathrm{H}$ ). In addition, rupture of the trans-Golgi network (Figure 4E,G; white asterisk) and cytoplasmic vacuolization (Figure 4D) were also observed.

To confirm that $\mathbf{1}$ induces an alteration in the mitochondria, the parasite $\Delta \Psi_{\mathrm{m}}$ was measured using JC-1, a cationic mitochondrial vital dye. This dye is lipophilic and concentrates in mitochondria in proportion to the membrane potential; increased dye accumulation is observed in mitochondria with greater $\Delta \Psi_{\mathrm{m}}$. The spectrofluorometric data presented in 

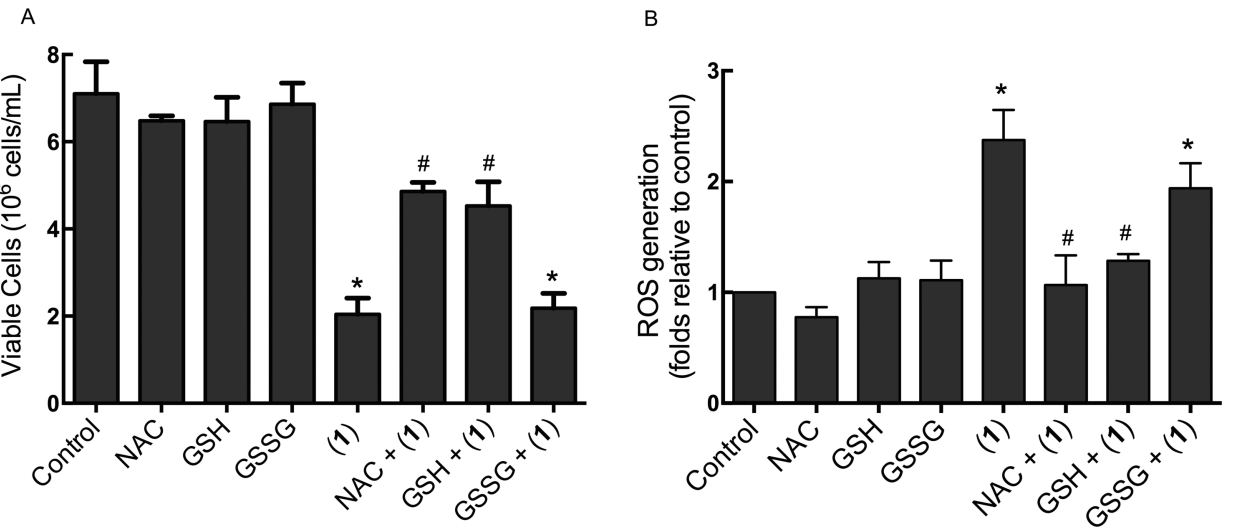

Figure 3. Effect of thiol antioxidants on apigenin-induced inhibition of cellular proliferation (A) and ROS generation (B). L. amazonensis was cultivated in Schneider's Drosophila medium at $26^{\circ} \mathrm{C}$ as described in the Experimental Section for $24 \mathrm{~h}$ in the presence of $\mathrm{N}$-acetyl-L-cysteine (NAC), reduced glutathione (GSH), or oxidized glutathione (GSSG) in the absence or presence of 1. NAC, GSH, or GSSG was solubilized in phosphate buffered saline and added to the culture at a final concentration of $300 \mu \mathrm{M}$. Compound 1 was solubilized in dimethylsulfoxide (DMSO) and added to the culture at a final concentration of $96 \mu \mathrm{M}$. The values shown are the mean \pm standard error of three different experiments. In the control (absence of 1 ), the same volume of vehicle (0.2\% DMSO) was added to the growth medium. ROS generation was measured using the fluorescent dye $\mathrm{H}_{2}$ DCFDA as described in Experimental Section. The data are expressed as the fold increase in ROS production relative to the control. The values shown are the mean \pm standard error of three different experiments. CTRL, control; *indicates significant difference relative to

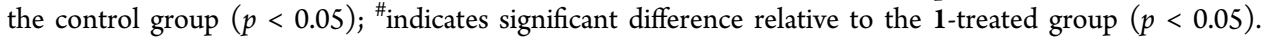

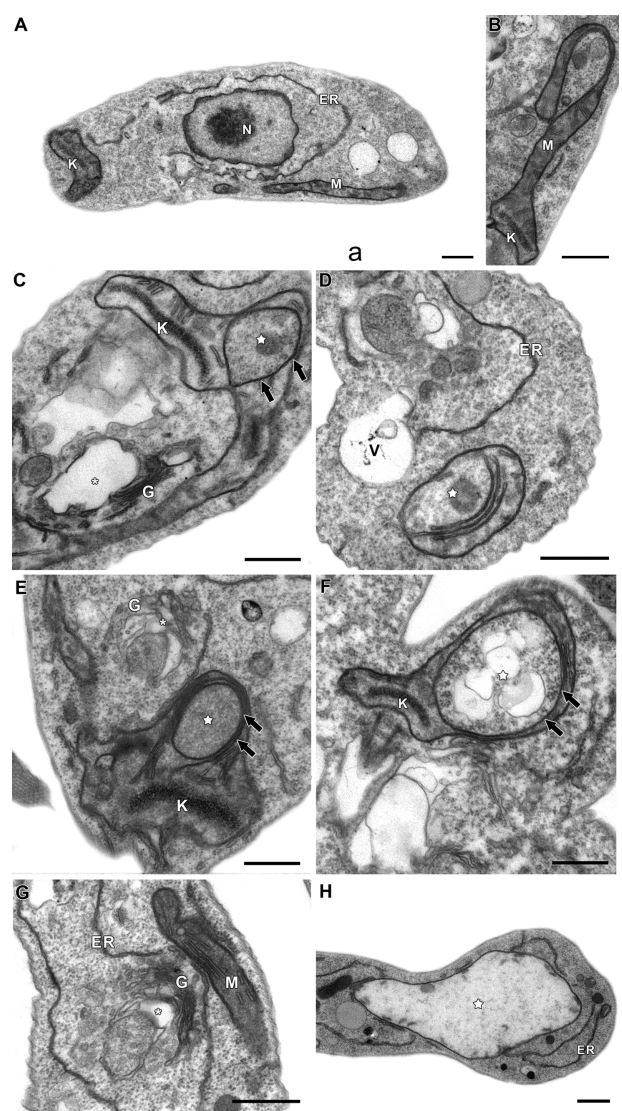

Figure 4. Ultrastructural alterations in L. amazonensis promastigotes treated with compound $\mathbf{1}$. Untreated parasites $(\mathrm{A}, \mathrm{B})$ presented typical elongated morphology with normal kinetoplast $(\mathrm{K})$, mitochondria $(\mathrm{M})$, endoplasmatic reticulum (ER), and nucleus $(\mathrm{N})$. Promastigotes treated with $12 \mu \mathrm{M}(\mathrm{C}, \mathrm{D}), 24 \mu \mathrm{M}(\mathrm{E}-\mathrm{G})$, or $96 \mu \mathrm{M}(\mathrm{H}) 1$ exhibited extensive swelling of the parasite mitochondria, with a washed-out matrix appearance (white stars) and the presence of concentric membrane structures inside the organelle (black arrow). Rupture of the trans-Golgi network (white asterisk) and cytoplasmic vacuolization (V) were observed. All scale bars correspond to $0.5 \mu \mathrm{m}$.
Figure 5A indicate a marked concentration-dependent decrease in the relative fluorescence intensity $\left(\Delta \Psi_{\mathrm{m}}\right.$ values $)(p<0.001)$. These results indicate membrane potential depolarization in cells upon treatment with $1(3-96 \mu \mathrm{M}) . \Delta \Psi_{\mathrm{m}}$ was reduced by $78.3 \%$ upon treatment with $96 \mu \mathrm{M}$ compound 1. Decreased relative fluorescence intensity values were also observed following treatment with $20 \mu \mathrm{M}$ FCCP (79.8\% reduction). A linear correlation $\left(R^{2}=0.9325\right)$ was observed between the alteration of $\Delta \Psi_{\mathrm{m}}$ and inhibition of $L$. amazonensis proliferation by 1 (Figure $5 B$ ). Therefore, we suggest that 1 exerts its antileishmanial effect on $L$. amazonensis via ROS production followed by a loss of $\Delta \Psi_{\mathrm{m}}$.

The mitochondria of Leishmania spp. are an exceptional chemotherapeutic target due to their unique structure, which is functionally distinct from that of mammalian mitochondria. Ultrastructural disorganization of the mitochondria was observed in promastigotes treated with $\mathbf{1}$, confirmed by the decrease in $\Delta \Psi_{\mathrm{m}}$.

Mitochondria are responsible for respiration and oxidative phosphorylation in eukaryotic cells, including trypanosomatides, and they provide ATP via respiratory-coupled oxidative phosphorylation. During oxidative phosphorylation, electrons are transported through the mitochondrial respiratory chain, and a proton gradient is established across the inner mitochondrial membrane as the energy source for ATP production. ${ }^{26}$ The observed decrease in $\Delta \Psi_{\mathrm{m}}$ suggests increased proton permeability across the inner mitochondrial membrane, which would lead to a decrease in ATP synthesis and, ultimately, lead to parasite death. Ultrastructural alterations and collapse of $\Delta \Psi_{\mathrm{m}}$ have been observed in L. amazonensis, ${ }^{10,27}$ L. donovani, ${ }^{28-30}$ and $T$. $\mathrm{cruzi}^{31-33}$ after treatment with various drugs.

In conclusion, these results demonstrate the leishmanicidal effect of apigenin (1) and suggest the involvement of ROS leading to mitochondrial collapse as part of the mechanism of action. These results support $\mathbf{1}$ as a possible candidate for leishmaniasis chemotherapy. Further studies are needed to confirm this effect in a murine experimental model of leishmaniasis infection. 
A
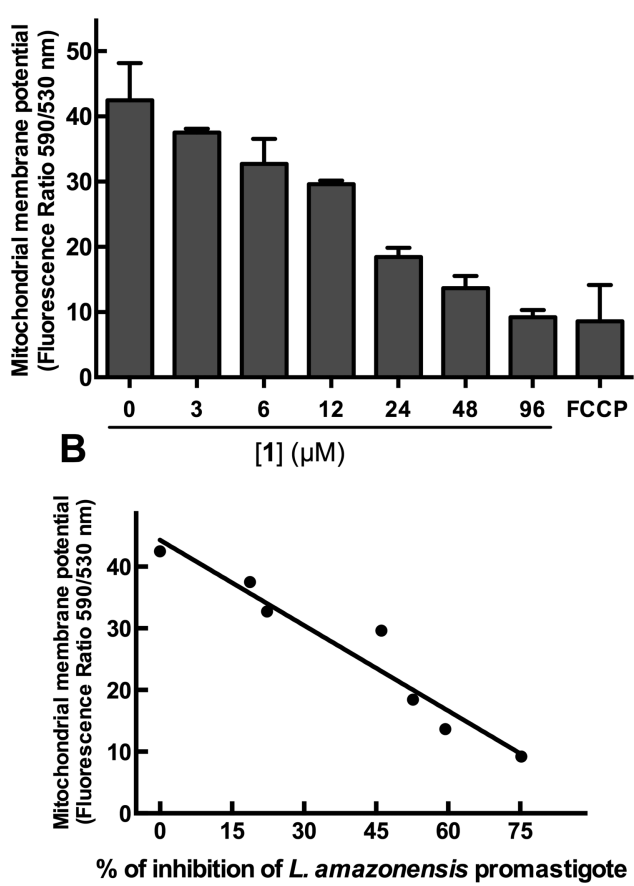

Figure 5. Evaluation of the mitochondrial membrane potential of Leishmania amazonensis promastigotes treated with 1. Leishmania amazonensis was cultivated in Schneider's Drosophila medium at $26{ }^{\circ} \mathrm{C}$ for $24 \mathrm{~h}$ in the absence or presence of $1(3-96 \mu \mathrm{M})$. Promastigotes were labeled with the potentiometric probe JC-1 $(10 \mu \mathrm{g} / \mathrm{mL})(\mathrm{A})$. The positive control was treated with FCCP $(20 \mu \mathrm{M})$ for $20 \mathrm{~min}$. In the control (absence of $\mathbf{1}$ ), the same volume of vehicle (0.2\% DMSO) was added to the growth medium. Concentration-dependent alterations in relative $\Delta \Psi_{\mathrm{m}}$ values are expressed as the ratio of the fluorescence measurements at $590 \mathrm{~nm}$ (for J-aggregate) versus $530 \mathrm{~nm}$ (for Jmonomer). The data are expressed as the means \pm standard errors of three different experiments. (B) Correlation between the alteration of $\Delta \Psi_{\mathrm{m}}$ and inhibition of $L$. amazonensis proliferation by $\mathbf{1}\left(R^{2}=0.9325\right)$.

\section{EXPERIMENTAL SECTION}

Test Compound and Reagents. Apigenin (1) (100\% purity; lot 081M1457 V), Schneider's Drosophila medium, fetal calf serum, RPMI-1640 medium, penicillin, streptomycin, JC-1 (5,5',6,6'-tetrachloro-1,1',3,3'-tetraethylimidacarbocyanine iodide), $N$-acetyl-L-cysteine, reduced glutathione, oxidized glutathione, glutaraldehyde, sodium cacodylate, osmium tetroxide, potassium ferricyanide, uranyl acetate, and FCCP [carbonyl cyanide 4-(trifluoromethoxy)phenylhydrazone] were obtained from Sigma-Aldrich (St. Louis, MO, USA). $\mathrm{H}_{2}$ DCFDA $\left(2^{\prime}, 7^{\prime}\right.$-dichlorodihydrofluorescein diacetate $)$ and 5,6carboxyfluorescein succinimidyl ester were obtained from Invitrogen Molecular Probes (Leiden, The Netherlands). All other reagents were purchased from Merck (São Paulo, Brazil). Deionized distilled water obtained using a Milli-Q system (Millipore Corp., Bedford, MA, USA) was used to prepare all solutions. Apigenin 1 was prepared in DMSO and diluted in culture medium such that the solvent concentration did not exceed $0.2 \%$ in the final solution.

Parasites. The MHOM/BR/75/LTB0016 strain of L. amazonensis was used throughout this study. This strain was isolated from a human case of cutaneous leishmaniasis in Brazil. Promastigotes were cultivated at $26{ }^{\circ} \mathrm{C}$ in Schneider medium ( $\mathrm{pH}$ 7.2) supplemented with $100 \mathrm{U} / \mathrm{mL}$ penicillin, $100 \mu \mathrm{g} / \mathrm{mL}$ streptomycin, and $10 \%(\mathrm{v} / \mathrm{v})$ heat-inactivated fetal calf serum.

Evaluation of Cellular Proliferation Using a Neubauer Chamber. Promastigotes were seeded into fresh medium $(1.0 \mathrm{~mL}$ final volume) either in the absence ( $2 \mu \mathrm{L}$ of DMSO) or the presence of various concentrations of $1(2 \mu \mathrm{L} ; 3-96 \mu \mathrm{M})$. The cells were maintained for $24 \mathrm{~h}$ at $26{ }^{\circ} \mathrm{C}$. Cell density was estimated using a Neubauer chamber. The proliferation curve was initiated with $1.0 \times 10^{6}$ cells $/ \mathrm{mL}$. The $50 \%$ inhibitory concentration $\left(\mathrm{IC}_{50}\right)$ was determined by logarithmic regression analysis using GraphPad Prism 6 (GraphPad Software, La Jolla, CA, USA).

Evaluation of Cellular Proliferation Using CFSE. Promastigotes $\left(2.5 \times 10^{7}\right.$ cells $\left./ \mathrm{mL}\right)$ were washed three times with phosphate buffered saline (PBS) and resuspended in PBS with albumin $(0.1 \%)$ and CFSE $(10 \mu \mathrm{M})$. The parasites were incubated at $26^{\circ} \mathrm{C}$ for $15 \mathrm{~min}$, during which they were carefully mixed three times. Staining was stopped by the addition of ice-cold medium. Stained promastigotes were centrifuged at $1500 \mathrm{~g}$ for $15 \mathrm{~min}$ at $4{ }^{\circ} \mathrm{C}$ and resuspended in fresh medium $\left(1.0 \times 10^{6}\right.$ cells $\left./ \mathrm{mL}\right)$ either in the absence $(0.2 \%$ DMSO $)$ or the presence of various concentrations of $1(3-96 \mu \mathrm{M})$. The cells were maintained for $24 \mathrm{~h}$ at $26^{\circ} \mathrm{C}$. Data acquisition and analysis were performed using a FACSCalibur flow cytometer (Becton Dickinson, Franklin Lakes, NJ, USA) equipped with Cell Quest software (Joseph Trotter, Scripps Research Institute, La Jolla, CA, USA). A total of 10000 events were acquired in the region previously established as corresponding to the parasites.

Measurement of ROS Levels. Intracellular ROS levels in promastigotes treated with 1 or untreated were measured using the cell-permeable dye $\mathrm{H}_{2}$ DCFDA. Promastigotes $\left(5 \times 10^{6}\right.$ cells $\left./ \mathrm{mL}\right)$ were cultured for $24 \mathrm{~h}$ in the absence or presence of 1 (3-96 $\mu \mathrm{M})$, harvested, and resuspended in Hanks' balance salt solution (HBSS), and $1 \times 10^{7}$ cells $/ \mathrm{mL}$ were incubated with $\mathrm{H}_{2}$ DCFDA $(20 \mu \mathrm{M})$ for $20 \mathrm{~min}$ at $26^{\circ} \mathrm{C}$. Data acquisition and analysis were performed by flow cytometry as described above.

Transmission Electron Microscopy Analysis. Promastigotes $\left(5 \times 10^{6}\right.$ cells $\left./ \mathrm{mL}\right)$ were treated with $1(12-96 \mu \mathrm{M})$ for $24 \mathrm{~h}$ in Schneider medium at $26{ }^{\circ} \mathrm{C}$. After being washed with PBS, the parasites were fixed in $2.5 \%$ glutaraldehyde in $0.1 \mathrm{M}$ sodium cacodylate buffer ( $\mathrm{pH} \mathrm{7.2)} \mathrm{at} \mathrm{room} \mathrm{temperature} \mathrm{for} 40 \mathrm{~min}$ and postfixed in a solution of $1 \%$ osmium tetroxide, $0.8 \%$ potassium ferricyanide, and $2.5 \mathrm{mM} \mathrm{CaCl} 2$ for $20 \mathrm{~min}$. The cells were dehydrated in an acetone series and embedded in a PolyBed 812 resin. ${ }^{34}$ Ultrathin sections were stained with uranyl acetate and lead citrate and examined using a JEOL 1011 transmission electron microscope (Tokyo, Japan) in the Plataforma de Microscopia Eletrônica, IOC, Fiocruz.

Determination of $\Delta \Psi_{\mathrm{m}}$. The cationic probe JC-1 was used to determine the $\Delta \Psi_{\mathrm{m}}$ as described. ${ }^{10}$ Promastigotes $\left(5 \times 10^{6}\right.$ cells $\left./ \mathrm{mL}\right)$ were cultured for $24 \mathrm{~h}$ in the absence or presence of $1(3-96 \mu \mathrm{M})$. Cells were harvested and resuspended in HBSS. The cell number was obtained via counting in a Neubauer chamber. Promastigotes $\left(1 \times 10^{7}\right.$ cells $\left./ \mathrm{mL}\right)$ were incubated with JC-1 $(10 \mu \mathrm{g} / \mathrm{mL})$ for $10 \mathrm{~min}$ at $26{ }^{\circ} \mathrm{C}$. After being washed twice with HBSS, fluorescence was measured spectrofluorometrically at 530 and $590 \mathrm{~nm}$ using an excitation wavelength of $480 \mathrm{~nm}$. The ratio of values obtained at 590 and $530 \mathrm{~nm}$ was plotted as the relative $\Delta \Psi_{\mathrm{m}}$. The mitochondrial uncoupling agent carbonyl cyanide $p$-(trifluoromethoxy)phenylhydrazone $(20 \mu \mathrm{M})$ was used as a positive control.

Statistical Analysis. All experiments were performed in three independent trials. The data were analyzed using Student's $t$ test or analysis of variance (ANOVA) followed by Bonferroni's post-test in GraphPad Prism 6 (GraphPad Software, La Jolla, CA, USA). The results were considered significant when $p \leq 0.05$. The data are expressed as the mean \pm standard error.

\section{AUTHOR INFORMATION}

\section{Corresponding Author}

*E-mail: elmo@ioc.fiocruz.br. Tel: +55(21)3865-8220. Fax: $+55(21) 3865-8200$.

\section{Notes}

The authors declare no competing financial interest.

\section{ACKNOWLEDGMENTS}

This work was supported by the Fundação Carlos Chagas Filho de Amparo à Pesquisa do Estado do Rio de Janeiro (FAPERJ to 
E.E.A.-A.); the Conselho Nacional de Desenvolvimento Científico e Tecnológico (CNPq/Universal Grant 470627/ 2013-1 to E.E.A.-A.); the Conselho Nacional de Desenvolvimento Científico e Tecnológico/Programa Estratégico de Apoio à Pesquisa em Saúde (CNPq/PAPES Grant 407590/ 2012-9 to E.E.A.-A.); and the Instituto Oswaldo Cruz/ Fundação Oswaldo Cruz (IOC/Fiocruz).

\section{REFERENCES}

(1) Kaye, P.; Scott, P. Nat. Rev. Microbiol. 2011, 9, 604-615.

(2) Alvar, J.; Velez, I. D.; Bern, C.; Herrero, M.; Desjeux, P.; Cano, J.; Jannin, J.; den Boer, M.; et al. PLoS One 2012, 7, e35671.

(3) Tiuman, T. S.; Santos, A. O.; Ueda-Nakamura, T.; Filho, B. P. D.; Nakamura, C. V. Int. J. Infect. Dis. 2011, 15, e525-e532.

(4) McGwire, B. S.; Satoskar, A. R. QJM 2014, 107, 7-14.

(5) Ioset, J. R.; Chang, S. Future Med. Chem. 2011, 3, 1361-1371.

(6) Ndjonka, D.; Rapado, L. N.; Silber, A. M.; Liebau, E.; Wrenger, C. Int. J. Mol. Sci. 2013, 14, 3395-3439.

(7) Salem, M. M.; Werbovetz, K. A. Curr. Med. Chem. 2006, 13, 2571-2598.

(8) Inacio, J. D.; Canto-Cavalheiro, M. M.; Almeida-Amaral, E. E. J. Nat. Prod. 2013, 76, 1993-1996.

(9) Inacio, J. D.; Canto-Cavalheiro, M. M.; Menna-Barreto, R. F.; Almeida-Amaral, E. E. Exp. Parasitol. 2012, 132, 151-155.

(10) Fonseca-Silva, F.; Inacio, J. D.; Canto-Cavalheiro, M. M.; Almeida-Amaral, E. E. PLoS One 2011, 6, e14666.

(11) Fonseca-Silva, F.; Inacio, J. D.; Canto-Cavalheiro, M. M.; Almeida-Amaral, E. E. J. Nat. Prod. 2013, 76, 1505-1508.

(12) Inacio, J. D.; Gervazoni, L.; Canto-Cavalheiro, M. M.; AlmeidaAmaral, E. E. PLoS Neglected Trop. Dis. 2014, 8, e3093.

(13) Shukla, S.; Gupta, S. Pharm. Res. 2010, 27, 962-978.

(14) Singh, M.; Kaur, M.; Silakari, O. Eur. J. Med. Chem. 2014, 84C, 206-239.

(15) Tasdemir, D.; Kaiser, M.; Brun, R.; Yardley, V.; Schmidt, T. J.; Tosun, F.; Ruedi, P. Antimicrob. Agents Chemother. 2006, 50, 13521364.

(16) Mead, J.; McNair, N. FEMS Microbiol. Lett. 2006, 259, 153-157.

(17) Messaritakis, I.; Mazeris, A.; Koutala, E.; Antoniou, M. Exp. Parasitol. 2010, 125, 384-388.

(18) Kamau, S. W.; Nunez, R.; Grimm, F. BMC Pharmacol. 2001, 1, 1.

(19) Lyons, A. B. J. Immunol. Methods 2000, 243, 147-154.

(20) Lapidot, T.; Walker, M. D.; Kanner, J. J. Agric. Food Chem. 2002, 50, $7220-7225$.

(21) Castro-Pinto, D. B.; Lima, E. L.; Cunha, A. S.; Genestra, M.; De Leo, R. M.; Monteiro, F.; Leon, L. L. J. Enzyme Inhib. Med. Chem. 2007, 22, 71-75.

(22) Issels, R. D.; Nagele, A.; Eckert, K. G.; Wilmanns, W. Biochem. Pharmacol. 1988, 37, 881-888.

(23) Amer, A. O.; Swanson, M. S. Curr. Opin. Microbiol. 2002, 5, 5661.

(24) Satoh, T.; Enokido, Y.; Aoshima, H.; Uchiyama, Y.; Hatanaka, H. J. Neurosci. Res. 1997, 50, 413-420.

(25) Dvorakova, K.; Waltmire, C. N.; Payne, C. M.; Tome, M. E.; Briehl, M. M.; Dorr, R. T. Blood 2001, 97, 3544-3551.

(26) Bermudez, R.; Dagger, F.; D’Aquino, J. A.; Benaim, G.; Dawidowicz, K. Mol. Biochem. Parasitol. 1997, 90, 43-54.

(27) Khouri, R.; Novais, F.; Santana, G.; de Oliveira, C. I.; Vannier dos Santos, M. A.; Barral, A.; Barral-Netto, M.; Van Weyenbergh, J. PLoS One 2010, 5, e14394.

(28) Roy, A.; Ganguly, A.; Bosedasgupta, S.; Das, B. B.; Pal, C.; Jaisankar, P.; Majumder, H. K. Mol. Pharmacol. 2008, 74, 1292-1307.

(29) Sen, N.; Banerjee, B.; Das, B. B.; Ganguly, A.; Sen, T.; Pramanik, S.; Mukhopadhyay, S.; Majumder, H. K. Cell Death Differ. 2007, 14, $358-367$.

(30) Sen, N.; Das, B. B.; Ganguly, A.; Mukherjee, T.; Tripathi, G.; Bandyopadhyay, S.; Rakshit, S.; Sen, T.; Majumder, H. K. Cell Death Differ. 2004, 11, 924-936.
(31) Menna-Barreto, R. F.; Correa, J. R.; Pinto, A. V.; Soares, M. J.; de Castro, S. L. Parasitol. Res. 2007, 101, 895-905.

(32) Menna-Barreto, R. F.; Goncalves, R. L.; Costa, E. M.; Silva, R. S.; Pinto, A. V.; Oliveira, M. F.; de Castro, S. L. Free Radical Biol. Med. 2009, 47, 644-653.

(33) Santa-Rita, R. M.; Lira, R.; Barbosa, H. S.; Urbina, J. A.; de Castro, S. L. J. Antimicrob. Chemother. 2005, 55, 780-784.

(34) Menna-Barreto, R. F.; Henriques-Pons, A.; Pinto, A. V.; Morgado-Diaz, J. A.; Soares, M. J.; De Castro, S. L. J. Antimicrob. Chemother. 2005, 56, 1034-1041. 